But the problems are legion, and I feel inclined to reverse the idea of Mackenzie's and to suggest that an attempt to add to medical knowledge by the investigation of particular problems would inevitably produce a better general practitioner and, incidentally, would not fail in its objective.

The point of view of the country doctor is largely epidemiological, and that in its widest sense. If he were to find a proportion of his young girl patients victims of enlargement of the thyroid gland it would be fitting of him to inquire into the local conditions and to attempt to find out if there were anything in these which might contribute to the knowledge of its causation. He might then suggest a more generous fish diet-fish is not a common article in the country diet-even if it came from the village shop in tins. He might suggest the use of iodized salt as a routine, or he might even persuade his local M.O.H. to add iodine to the water supply.

There are problems of heredity which are readily available : the hereditary nature of skin diseases such as psoriasis, of rheumatic heart disease, as well as more obvious hereditary diseases such as Huntington's chorea or Friedreich's ataxia, and conditions such as polydactyly. There are also many problems in the study of epidemic disease waiting to be solved.

Writers of textbooks on infectious disease are handicapped, and are too often bound to give approximations, say, in the length of incubation period and the duration of infectivity for want of definite information. Yet this information lies within the grasp of the country practitioner if he be interested and will give his mind to it.

In country places that short and only possible exposure which alone gives this accurate information can very often be traced in a way which is well-nigh an impossibility in a town, with the varied experience of the town dweller. Country doctors should all read William Budd's Typhoid Fever and realize in those pages how great are their opportunities and how much better and more interesting would be their work if the lead which lies close to hand were assiduously followed. Work of this sort in the field is a possibility in itself, but its value would be greatly enhanced should the practitioner form a close liaison with the director of a laboratory. This helpful co-operation is now possible, or will be possible to all in the future.

Lastly, there must be a bond between the general practitioner and the medical officer of health and the Health Services. May I plead with the M.O.H. to get to know all the general practitioners in his area and to be willing at all times to give them his help ?

Research is not a matter of gusts of inspiration but the result of patient observation undertaken with no thought of self-advancement. "In the fields of observation chance favours only the mind which is prepared." So wrote Pasteur. May those of us in general practice see that our minds are thus prepared.

A Clean Food Association has recently been formed in Caernarvonshire. It will have as its primary objects the safeguarding of the people's health and raising the hygienic standards of food production and handling. Representatives and officers of all the local sanitary authorities and of the county council, together with elected representatives of food production and handling organizations in the county, will be members of the Association. All restaurants, cafés, milk bars, etc., will be encouraged to attain and maintain a prescribed standard of cleanliness and hygiene in the preparation and handling of food, and to each establishment attaining the standard will be given an authorized certificate for display. Educational talks and film displays will be arranged for food handlers, and scientific information will be distributed to all those concerned. According to Dr. D. E. Parry-Pritchard, the County Medical Officer, Caernarvonshire is the first county in England and Wales to direct combined and co-operative efforts in this direction.

\section{MEDICAL EDUCATION IN THE UNITED STATES}

\author{
BY
}

RAYMOND WHITEHEAD, D.Sc., M.D.

(From the Department of Pathology, University of Manchester)

From the British standpoint the study of American medical education is valuable chiefly because it throws into relief the characteristic features of our own system. Although they have much in common, the British and American systems of medical education each have many distinctive features. These are expressions of the different historical circumstances of the two nations, and the possibilities of directly transferring the methods of one country to the other are accordingly limited. Mutual influence is more likely to be fruitful; ideas and principles travel better than particular applications of them, and, if adopted, it is best that they should take forms suited to the national genius. It will be helpful first of all to describe the American institutions concerned in medical education.

\section{Colleges}

The highest form of general education is given in colleges of liberal arts and sciences. These institutions have no British counterpart ; they are neither schools nor universities but have features of both. Some colleges are independent, under a president ; others form part of a university, when they are administered by a dean. There seems to be no essential difference betwen the independent and the university colleges. The primary purpose of a college is to give general education of an advanced type, but professional subjects such as engineering are sometimes taught; research work is not a normal function of a college even when it forms part of a university.

Students enter colleges as a rule at the age of 18 and follow a four-year course, receiving at its close the degree of Bachelor of Arts (A.B.) or Bachelor of Science (B.S.). The degree is obtained by accumulating a required number of credits. These are records of the satisfactory completion of a certain number of hours in a course, as shown by examinations conducted by the instructor who gives the course. Comprehensive examinations similar to those in British universities are unusual. The standard of the American college degree is probably about the same as that of a British pass degree. The difference between American college degrees and British university degrees with the same titles lies not so much in the standard as in the range of knowledge required; for American degrees this is usually wider and less directly vocational than that represented by a British B.A. or B.Sc.

\section{Universities}

The typical American university consists of a college of the kind described above and a variable number of professional schools. The term faculty is used in two senses : first, in the abstract British sense of a main division of university work, particularly postgraduate work, and, secondly, to denote the staff ("the faculty" is exactly equivalent to "the teaching staff" in British usage). The college and each school are administered by deans; their powers are wide, resembling those of an English vicechancellor, and the relation between a dean and the professors of his school is similar to that between the vicechancellor and the senate of a modern English university. The chief officer of a university is the president, and the governing body a board of trustees-men of standing in 
business or the professions. Each school manages its own affairs but is responsible to a central administration.

Students reading for higher degrees are known as " graduate students." Such students work in any building (college or professional school) with the necessary facilities, but all are deemed to belong to the "graduate school " of the university irrespective of their field of work. Although it has no buildings, the graduate school has a dean. Not all graduate students are research students; most of them read for the degrees of Master of Arts (A.M.) or Master of Science (M.S.). Training in research methods is usually given to candidates who have matriculated for the degree of Doctor of Philosophy (Ph.D.).

The professional schools often require their students to be college graduates. Work in such a school for a number of years leads to a professional degree, that of bachelor, except in medicine and related fields such as dentistry, in which it is a doctorate ; originally the initial medical degree was M.B., but this has virtually disappeared. Surgery and obstetrics are not recognized by special degrees.

The most important non-professional degree is the Ph.D. This is awarded by the graduate school for work in any field of knowledge (including medicine) and is normally held by those teachers in medical schools who are not medically qualified. The Ph.D. can be obtained by three years' work after graduation as a bachelor at a college, but often four years are spent on it. The course consists partly in research work (on which a thesis is required) and partly in study similar in nature to an honours course for British undergraduates. The final examination is of a high standard and includes a searching oral test. The D.Sc. degree is normally awarded only honoris causa.

Some universities are private, being financed (apart from fees) by income from endowments, by gifts from private persons, or by grants from foundations; others are State or municipal institutions. Both types-the private and non-private-are organized on the same lines, and it is doubtful whether they differ in quality.

College and university students may live where they please. Many institutions have halls of residence known as "dormitories." Fraternities, which are student clubs and in many cases wealthy corporations, also maintain club-houses where the members may reside. The fraternities are often national organizations, and a single fraternity may maintain a house at each of many colleges and universities. Some fraternities are professional, their houses being reserved for students preparing for a specified profession. The corresponding organizations for women are known as sororities.

\section{Medical Schools}

Until the chaotic state of medical education in the United States was revealed in a report prepared by Mr. Abraham Flexner about forty years ago, many medical schools were notoriously inefficient. As a result of this report, about half the medical schools disappeared and standards were set up under the auspices of the American Medical Association and the Association of American Medical Colleges. The result is that the United States now possesses some of the best-designed and best-equipped medical schools in the world.

The first great American school, that of the Johns Hopkins University, Baltimore, was opened in 1893 . The Johns Hopkins medical school is famous for many things ; only three can be mentioned here : (1) it was the first American embodiment of the research spirit of nineteenthcentury German medicine ; (2) it set an example by requiring a high standard of general education in candidates for admission ; and (3) it introduced, in 1914, the system of a full-time teaching staff in the clinical branches of medicine, thus placing the whole of medicine on a university basis.

The full-time system is now an accepted principle of medical education in the United States and has recently become so familiar in this country that no description of it is necessary. It is, however, worth noting that, like the full-time clinicians, the full-time pathologists are primarily teachers and research workers rather than routinists. The routine pathology-necropsies and surgical histology-is done (under supervision) by young clinicians who also share in the teaching of students. This arrangement benefits all concerned: (1) the clinicians, who receive a valuable training in the correlation of signs and symptoms with structural changes; (2) the students, who are largely taught by men with up-to-date knowledge of the clinical branches of medicine; (3) the full-time pathologists, who have adequate time for research; and (4) the hospital staff, whose heavy demands can easily be met owing to the number of routinists available.

At the Johns Hopkins University the medical school and hospital occupy separate buildings, but modern opinion favours the union of school and hospital in a single building. For example, at Rochester, New York, where a medical school was opened in 1925, a single building houses the medical school, the university hospital, and the municipal hospital, which for all medical purposes form a single institution. The plan of a single building was adopted with the object of promoting the closest possible co-operation between all departments, clinical and non-clinical, in teaching and research. The plan has the further advantage that duplication of services is avoided-the whole institution is served by a single workshop, animal house, photographic department, and pathological laboratory.

American medical schools are inspected and graded by the American Medical Association, which indicates shortcomings privately to the schools concerned; the American Medical Association thus performs functions that in this country would be regarded as appropriate to an official body.

The Johns Hopkins medical school has in the course of time lost its unique distinction owing to the rise of other first-rate schools. How many schools may properly be so described is a matter of opinion, but there is general agreement among American medical teachers that about twelve schools now qualify.

\section{The Medical Curriculum}

Pre-medical education is obtained in colleges. For prospective medical students the college course includes chemistry, physics, botany, zoology, English, and either French or German. In his final college year the student takes the scholastic aptitude test of the Association of American Medical Colleges. This is a test of (1) comprehension and retention of a previously unseen mass of facts, (2) visual memory, (3) memory for content of an anatomical diagram, (4) general information, (5) logical reasoning, (6) scientific vocabulary, and (7) understanding of printed material. The student's performance in this test, details of his standing in college, and reports from his science teachers are considered by the medical school and promising candidates are interviewed. On account of this careful selection most of the students admitted complete the course.

The medical course lasts four years, the first two being preclinical, the last two clinical. The subjects of study are substantially the same as in this country, but the systematic courses of instruction in pharmacology, pathology, and bacteriology are completed before clinical work is begun. Towards the end of the preclinical period 
instruction in clinical methods is given. The clinical period is spent first in the wards, later in the out-patient departments. On completing his course the student receives as a rule the degree of M.D., which qualifies him for an internship (house appointment). The right to practise independently is obtained by passing one of the State examinations or the final of the National Board (roughly equivalent to the Conjoint Board). Many States require candidates for their examinations to have completed one year of internship.

\section{Methods of Teaching and Examining}

The student's work is carefully planned and supervised. In most subjects there is one teacher to every three or four students. Each teacher forms an estimate of each student, taking into account character and personality as well as ability. These estimates may be expressed as marks-as many as half the possible marks in a professional subject may be reserved for teachers' estimates, only half being obtainable at the examination. For this reason examinations are less important than they are in this country.

One or more subjects are commonly studied intensively all day and every day until the ground has been covered; in this way anatomy may be finished in six months, histology in three. The study of clinical subjects is similarly concentrated, each major and minor subdivision receiving so many months or weeks according to its importance. Throughout his course the student may spend most of the day ( 8.30 a.m. to 10 p.m.) in the laboratories, lecture rooms, or wards and has less time for reading than the British student. One or two half-days a week throughout the course may be kept free for work of the student's own choice-research work or an optional course.

During the clinical period the student has access to patients at all hours of the day and night. The student is an indispensable member of a team-the normal work of the hospital could not be done without him.

The standard of knowledge attained varies with the subject. In anatomy it is not so high as in this country, probably owing to the relatively short time spent on it and the consequent necessity for high-speed dissection. In biochemistry, on the other hand, the standard is much higher; in physiology, pharmacology, pathology, and bacteriology it is about the same. In the clinical subjects the student has more responsibility for his patients and does more routine work than in this country; on the other hand his experience, especially of obstetrics and emergency work, is often narrower than the Englishman's. Venereology receives more attention and forensic medicine less. Medical history is taught in some schools, forming one of the optional courses.

Perhaps the most distinctive feature of American medical teaching is the clinical-pathological conference. This is a standard form of instruction that the student attends once a week throughout the clinical period. The details of procedure vary in different schools, but the general plan can be seen from the following example. The conference takes place in the post-mortem room and lasts exactly one hour (12 noon to 1 p.m.). It is attended by all the staff of the pathology department, the radiologists, many clinicians besides those directly concerned with the cases studied, and all students qualified to attend. Three or four cases are presented on unfixed material that has been kept in a refrigerator. The following topics are dealt with in the order named : (1) clinical history, (2) $x$-ray report and demonstration of films by a radiologist, (3) comments by clinicians of "honorary" status, (4) post-mortem findings by the pathologist who performed the necropsy, (5) comments by the professor of pathology, who then answers questions,
(6) formal description of the organs by the professor of pathology, (7) questions and general discussion. Criticism of the diagnosis and treatment is frank and free, and there is no respect of persons by either colleagues or students.

\section{Discussion}

From the information given above it will be clear that the American system of medical education differs considerably from ours, and some of its main features will be briefly discussed.

The selection of medical students is a difficult problem and probably explains the introduction of the scholastic aptitude test. It should, however, be noted that this is only one of the various aids to prognosis, and that great importance is also attached to the interview.

The preclinical study of pharmacology, pathology, and bacteriology would not find favour with British teachers. An elementary knowledge of these subjects is necessary if the student is to profit by clinical instruction; the completion of the systematic courses in them before clinical work has begun is undesirable. This point may be illustrated with reference to pathology. The object of teaching pathology to medical students is to enable them to understand the changes in structure and function that occur in disease and so to interpret signs and symptoms accurately. The discussion of pathological phenomena that the student has not seen in patients is largely a waste of time; for this opinion there is ample evidence from the experience of dental students when they have been required to follow a pathology course designed for medical students. Under these conditions the dental students are often bewildered, and the pathological instruction conveys very little to them. The fact is, of course, that pathology and clinical medicine and surgery are not distinct subjects that can be profitably studied apart, but simply different approaches to a single problem-namely, the man who is ill. Ideally, pathological teaching should thus continue throughout the clinical period. In practice, however, this would mean overloading the final examination, and a sensible compromise is to hold the examination in pathology some time before the final in order to allow the student to concentrate on the clinical aspects of his work. If the intimate relation between pathology and clinical work be granted it follows that a pathology course for dental students should be specially designed, at least after the completion of the study of general pathology.

The high proportion of teachers to students in American schools makes it possible to give the students more individual attention than is practicable in this country and also puts at the student's disposal a wider range of interests and experience. The elaborate system of grading of the students by the teachers is probably a natural development made possible by the abundance of teachers.

The significance of examination results is not the same as in this country. The American student is judged on his knowledge, class work, and personality, the British student on his knowledge alone. A pass in a British examination means that the student has mastered the essentials of a subject; a pass in an American examination does not equally guarantee this, because a proportion of the marks may be awarded on grounds other than the demonstrated possession of knowledge.

The intensive system of teaching allows the student too little time for reading and rumination and denies him the relief of studying different subjects concurrently.

Clinical-pathological conferences are a valuable means of correlating clinical findings and pathological changes. They are valuable for students and even more so for clinicians and pathologists, who are thus regularly brought into 
conference. The conferences are most instructive when they relate to patients recently dead, since many of those attending will have seen the patient during life and will therefore have the problems of diagnosis and treatment vividly in mind; a conference on patients dead long ago is less instructive, despite the more complete documentation, including histological reports on material removed at necropsy. Since the main object of a conference is the instruction of students, the cases should preferably illustrate the common diseases, and the conference should be conducted throughout with the student's limited experience in mind; difficult cases requiring specialized clinical or pathological knowledge would be best discussed at conferences for graduates only.

\section{Summary}

The institutions concerned in medical education in the United States are described and the education of the American medical student is described and compared with that of the British student.

Medical education in America is conducted on the same general lines as in this country, and the subjects of study and their scope are substantially the same.

The distinctive features of American teaching are: (1) the sharp separation of non-clinical from clinical studies, (2) the high proportion of teachers to students, (3) the important place of the student in the hospital team, (4) the relative unimportance of examinations, (5) the intensive system of study, and (6) clinical-pathological conferences.

One year of internship is a common prerequisite for independent practice.

I am indebted for discussions to many medical teachers, British and American, and to British students who worked in American schools during the war. I am grateful to Professor I. L. Kandel for expert advice on American education and to Professor S. L. Baker for reading the manuscript.

\section{Nova et Vetera}

\section{JOHN WILLIAMS AND THE EARLY HISTORY OF YELLOW FEVER BY}

\section{G. M. FINDLAY, C.B.E., M.D., F.R.C.P.}

The early history of most diseases is lost in the mists of time. This is not as a rule a matter of great importance, but in the case of yellow fever it would still be of considerable interest to know whether in historical times the infection had first passed from Africa to America or from America to Africa, or whether the evidence favours the view that the disease was present long before the coming of man, when Gondwanaland still included what is now South America and Africa. If the yellow fever virus could colonize a new continent in the sixteenth or seventeenth century it might conceivably do so once again.

One of the arguments which has always been used by those who favour the American origin of yellow fever has been that whereas the first recorded outbreak of the disease in the New World was in 1648 in Guadeloupe, Havana, and Yucatan (Du Tertre, 1667-71 ; López de Cogulludo, 1688), and almost certainly in 1647 in Barbados and St. Christopher (Ligon, 1657 ; Scott, fl. 1634-96; Winthrop, 1853), the first record of an outbreak in the Old World is not till 1778, when the Hessian, John Peter Schotte (1782), described yellow fever under the name of "synochus atrabiliosa" in St. Louis de Senegal.

An authentic record of yellow fever in Africa which considerably antedates Schotte has now been found. This occurs in a pamphlet published by John Williams at Kingston, Jamaica. The pamphlet is entitled "An Essay on the bilious or yellow fever of Jamaica." [Petet autem novum quoque consilium, non $a b$ rebus latentibus (istae. enim dubiae \& incertae sunt) sed ab his, quae explorari possunt; id est, evidentibus Causis.
A. Corn. Celsi Praef.] Kingston: Printed by William Daniell, Printer and Bookseller, at the New General Printing Office, the corner of Water Lane in King Street, near the Court House, 1750.

This little work seems to have had only a limited circulation. There is no copy in the British Museum, but one exists in the library of the University of Edinburgh and another in the Surgeon-General's Library in Washington.* The first edition was, however, reprinted in London in 1752 by $\mathrm{T}$. Waller, opposite Fetter Lane in Fleet Street, and was sold for the sum of two shillings. Of this edition there are more examples, as for reasons which will be detailed it created some general interest. Its significance, however, has been overlooked by those interested in the history of yellow fever. The "Essay on the bilious or yellow fever" met with considerable criticism from Parker Bennet, a physician resident in Jamaica, who wrote "An enquiry into the late Essay on the bilious fever." This inquiry stirred John Williams to a poetic flight in heroic couplets, after the manner of Mr. Pope, in "An Epistle to the Honourable Charles Price, Esq.," whereupon Bennet replied in "A prose epistle to a poetic epistle writer." This in its turn was followed by "A letter to Doctor Bennet" from Williams with the motto "The mouth of them that speak lies shall be stopped."-Psalms 1xiii. 11. This letter could not have been published until after Nov. 27, 1750, and was the last written communication between John Williams and Parker Bennet, for on Dec. 29 they came to blows which, in the words of the anonymous editor of the 1752 reprint, "terminated in the death of both." Before retailing this curious incident it is proposed to discuss the reference to yellow fever on the West Coast of Africa.

\section{Yellow Fever in West Africa}

Williams describes very accurately the symptoms of yellow fever as he knew it in Jamaica. He then goes on, "I do not apprehend this fever is what we call a local disorder; for I have seen it upon the coast of Africa, and am well informed that in the River Benin they have a bilious or yellow fever acuter than what it was here, at the time of the expedition to Carthagena; the persons seized with this fever dying there in less than twenty-four hours. This disorder is generally brought on by suddenly cooling the body and checking perspiration after hard exercise in the heat of the sun for when sailors go to cut wood for the ship's use they are obliged to row several leagues against a current and then jump into the water to carry the wood on shore.".

John Williams, it appears, had been a surgeon on a Guineaman, that is to say, a slave ship plying from Guinea to the West Indies, for Benret twits him with having gained most of his experience in treating African negroes on the coast of Guinea. Bennet, it may be noted, was an M.D. of Edinburgh, while Williams, who is always referred to by Bennet as "Mr. Williams," states that he had acquired his experience "like honest and careful Sydenham" and had "made himself acquainted with the diseases of the country ... never sacrificing his patient to any favourite hypothesis." That the assertion by Williams that he had seen yellow fever in Africa was not regarded as remarkable is seen from a statement by Bennet in his "Enquiry into the late Essay on the bilious fever." "We assure him," Bennet says, "that some of us have been in Africa, on board Guineamen, and in other islands of the West Indies as well as he, consequently we are equally entitled to write upon and cure the yellow fever. Physic is a science not to be acquired by mere dint of natural parts."

There is no doubt that Williams actually described yellow fever. According to him, "The distinguishing symptoms or diagnostics of this disorder are, besides what is common to fevers, great anxiety, heat and pain at the scrobiculum cordis, some degree of inflammation of the liver which frequently causes a jaundice, bilious vomiting or ejections, or both ; sometimes an acute, sometimes a dense pain about the region of the liver, all manifest signs of inflammation. Sometimes we find the right hypochonder tumified, frequently hard. Many cannot bear pressure on the right side or to lie on the left. From these symptoms to worse-strong and continued convulsions of the diaphragma, intercostal muscles and stomach, aeruginose

*A microfilm of the first edition is now in the library of the British Medical Association. 